\title{
How dear are deer volunteers: the efficiency of monitoring deer using teams of volunteers to conduct pellet group counts
}

\author{
Christina D. Buesching, Chris Nemman and David W. Macdonald
}

\begin{abstract}
Deer populations are increasing throughout the northern hemisphere, and unregulated numbers can jeopardize biodiversity and the economy. These populations are difficult to monitor using visual counts. Estimating densities from surveys of faecal pellets is reliable but timeconsuming and thus, if carried out by professionals, expensive. Utilizing volunteers has clear advantages. Based on research from the UK (6 years) and Nova Scotia, Canada (4 years), we investigated the methodological refinements and training required to achieve reliable data when using volunteers. For safety reasons volunteers worked in teams of $5^{-10}(\mathrm{n}=611)$ under supervision of scientists. We compared faecal accumulation rate and faecal standing crop surveys using $10 \times 10 \mathrm{~m}$ quadrats. Both methods produced similar estimates of density, but because of significant time savings and greater volunteer enjoyment we favour faecal standing crop over faecal accumulation rate surveys. Volunteer teams surveyed quadrats significantly faster than a single professional but needed significantly longer to reach and stake out new quadrats. On average, teams found $68 \%$ of all droppings. Performance of individuals was affected by training, gender, and willingness and aptitude to survey. After five quadrats men scored significantly higher than women but this difference was reduced after 20 quadrats. Age did not affect performance but willingness and aptitude correlated with ability to find and identify droppings. We conclude that volunteers can monitor deer effectively but that techniques should be modified. The provision of context, training, supervision and verification by a professional are essential. Because of the drain on scientists' time, costeffective volunteer deployment is a question of scale.
\end{abstract}

Keywords Calibration, citizen science, ecological surveying, motivation, training, validation, volunteer data

\section{Introduction}

onservation biologists recognize the need to engage the public in nature conservation (e.g. CBD, 1993). Public

Christina D. Buesching (Corresponding author), Chris Newman \& David W. MACDONALD Wildlife Conservation Research Unit, Department of Zoology, University of Oxford, The Recanati-Kaplan Centre, Tubney House, Tubney, Abingdon, OX13 5QL, UK. E-mail christina.buesching@zoo.ox.ac.uk

Received 24 October 2012. Revision requested 7 January 2013.

Accepted 18 January 2013. First published online 11 February 2014 engagement in the form of citizen science (Silvertown et al., 2013) can result in considerable benefits for ecological monitoring (Macdonald et al., 1998). However, not all methods are equally suitable for amateur participation because of training requirements, animal welfare, health and safety implications, and government licensing (Silvertown et al., 2013).

Species monitoring is an important component of habitat management and conservation strategies but can be repetitive, labour- and time-intensive (and thus costly if conducted by paid professionals), and often involves surveys on large geographical scales (Macdonald et al., 1998). Many tasks are well suited to public participation as they require little training (Newman et al., 2003) and are based on noninvasive field sign surveys (Macdonald et al., 1998).

The need for deer monitoring is well established (Macdonald et al., 1998), and field signs are easy to identify (Newman \& Buesching, 2004a,b). However, deer numbers are difficult to estimate reliably (Smart et al., 2004), highlighting the need for intensive monitoring. Deer population densities are increasing in Europe and North America, and species have expanded into previously deer-free areas (Fuller \& Gill, 2001). Deer can have significant adverse effects on forest ecosystems; e.g. trampling and browsing of tree saplings prevents regeneration (Gill, 2006), and increased browsing pressure results in decreasing numbers of small mammals (Buesching et al., 2011) and groundnesting birds (Gill \& Fuller, 2007). Deer can spread zoonotic diseases (Spielman, 1994) and can cause road traffic accidents.

Population estimates from counts of faecal pellet groups is a well-established method and is used extensively (Mayle \& Staines, 1998; Patterson et al., 2002). Several studies have assessed the design, veracity and analysis of such count surveys (Campbell et al., 2004), proceeding from the assumption that pellet groups can be recognized individually, because of species-specific pellet size and characteristics, discrete clumping, and apparent age differences. Counts of faecal pellet groups provide an ideal indirect method for volunteer deployments as population densities can be estimated without seeing the animals and, contrary to other methods (Mayle \& Staines, 1998), they do not require specialized equipment or licensing, can be performed in all habitat types (Macdonald et al., 1998), and can easily be taught to novices (Newman et al., 2003).

Two principal variants of the method exist. Faecal standing crop counts record the number of pellet groups in a 
TABLE 1 Description of the study sites in Wytham Woods, Oxfordshire, UK, and Cook's Lake Farm, Lunenburg County, Nova Scotia, Canada.

\begin{tabular}{lc}
\hline Wytham Woods & Cook's Lake Farm \\
\hline $1^{\circ} 20^{\prime} \mathrm{W} 51^{\circ} 46^{\prime} \mathrm{N}$; elevation $100-165 \mathrm{~m}$ & $64^{\circ} 40^{\prime} \mathrm{W} 44^{\circ} 26^{\prime} \mathrm{N}$; elevation $50-75 \mathrm{~m}$ \\
389 ha of mixed-species semi-natural, deciduous woodland, & 137 ha of mixed secondary coniferous \& deciduous woodland, \\
including c. 65 ha of rough grasslands, with several ponds \& & 12 ha of hay meadows, several ponds \& brooks \& c. 16 ha of \\
bordering the river Thames & wetland, in addition to lake shore \\
Monitored 2000-2005 & Monitored 2007-2010 \\
Multi-deer ecosystem with three deer species: fallow & Single-deer ecosystem with only white-tailed deer Odocoileus \\
Dama dama, roe Capreolus capreolus \& muntjac & virginianus (the farm is outside the remaining range of moose \\
Muntiacus reevesi (latter not monitored) & Alces alces americana) \\
Closed population: surrounded by $2 \mathrm{~m}$ high Tornado deer fence & Open population: site is unfenced, with deer moving between the \\
(Savill et al., 2010) & farm \& extensive areas of similar contiguous woodland \\
Managed by extensive winter culling 2000-2003 & Subject to provincially-managed recreational hunting; we thus \\
(Savill et al., 2010), with follow-up culls each winter to & estimate mean deer density over time \\
maintain a constant deer density & \\
\hline
\end{tabular}

random subsample of survey plots stratified by habitat type. Deer density is then extrapolated by taking into account the defecation rate per animal and the mean time for pellets to decay. The faecal accumulation rate requires permanent survey plots to be marked out, and the accumulation rate (number of new piles) is monitored weekly, necessitating return visits (Campbell et al., 2004). The disadvantage of both methodologies is large inter-plot variation in pellet group numbers, necessitating surveys of multiple plots per habitat type (Mayle et al., 1999).

Here we consider the practicalities and veracity of faecal standing crop and faecal accumulation rate surveys, as implemented by groups of amateur volunteers in the UK and in the province of Nova Scotia, Canada. In Nova Scotia deer are typically surveyed using 1,00o m line transects (in other provinces the methodology may vary according to climate, species and provincial laws), calculating winter accumulation based on time elapsed since leaf-fall (Patterson et al., 2002), but this proved impractical as volunteer expeditions tend to occur in summer. Thus, we opted to use quadrat surveys over line transects in both study areas, as recommended by the UK Forestry Commission (McIntosh et al., 1995).

Our objectives were three-fold. (1) We compared faecal standing crop with faecal accumulation rate to assess which technique is better suited to volunteer deployments; we investigated what training and refinements enhanced accuracy, developing a survey design suited to monitoring deer with volunteer groups. (2) We analysed whether volunteer teams, performing the same faecal pellet group count technique as professional biologists, could estimate deer densities reliably, and investigated whether enlisting volunteer groups could save the time and expense of professionals; we hypothesize that although all estimates will vary from reality, this is no truer of volunteers than of professionals. (3) We examined the factors affecting the ability of individual volunteers to estimate deer densities accurately and efficiently. All assessments were made relative to the performance expected from experienced professionals. Where possible, we calibrated our derived estimates against concurrent cull figures for a closed deer population in the UK.

\section{Methods}

\section{Study sites and volunteers}

A total of 611 volunteers, provided by the Earthwatch Institute, collected data on deer densities in Wytham Woods, Oxfordshire, UK (2000-2005; total of 356 volunteers) and in Cook's Lake Farm, Nova Scotia, Canada (2007-2010; total of 255 volunteers; Table 1). All surveys were conducted during May-August, to assimilate seasonal variability in accumulation and degradation rates (Campbell et al., 2004). Wytham Woods is a closed population surrounded by a deer fence. Cook's Lake Farm is an open population, surrounded by similar contiguous habitat.

Volunteer teams consisted of 8-14 members from diverse social and educational backgrounds (Buesching et al., in press). Earthwatch has a mandate of supporting science (Gilmour \& Saunders, 1995) and volunteer teams typified a cross-section of the public willing to participate in this type of conservation work. Earthwatch volunteers paid the organization GBP 150 for 5 days in the UK (accommodation and breakfast excluded) and CAD 2,500 for a 13-day expedition to Nova Scotia (all expenses except scientists' salaries included).

Volunteers were briefed about survey objectives and shown slides of deer droppings. For health and safety reasons volunteers were deployed as teams of 5-10 surveyors and were accompanied by at least one experienced professional biologist. Each volunteer participated only once. 


\section{Optimizing the survey method for volunteers}

In the first year at each site we compared the techniques for estimating faecal accumulation rate and faecal standing crop (Campbell et al., 2004), to assess their suitability for volunteer teams in terms of accuracy, repeatability and efficacy. For each survey volunteers lined up shoulder-to-shoulder along one edge of the $10 \times 10 \mathrm{~m}$ quadrat, thus effectively surveying individual $1-2 \times 10 \mathrm{~m}$ transects. Individual survey results were combined for each quadrat. Appropriate habitat stratification was achieved by defining forest characteristics important to deer; the extent of each stratum was calculated and sample quadrats were allocated proportionately (Plumptre \& Harris, 1995).

\section{Data analysis}

Calculation of deer abundance was based on the following variables, which were assumed to be independent: count $c$ (total number of pellet groups in the quadrat); production rate $p$ (defecation rate per animal per day), with fallow deer Dama dama producing 25 pellet groups per day (Mayle et al., 1999), roe deer Capreolus capreolus 17 pellet groups per day (Mitchell et al., 1985), and white-tailed deer Odocoileus virginianus 20 pellet groups per day (Patterson et al., 2002); decomposition rate $t$ (number of days after which $\geqslant 90 \%$ of pellet groups had decayed).

To determine faecal decomposition rate we established 20 decay plots in May and again in August to cover the whole survey season, each containing six pellet groups (three each of fallow and roe deer in Wytham Woods, and six of white-tailed deer in Nova Scotia, across all stratified habitats (Plumptre \& Harris, 1995). Fresh pellet groups were collected, the form of the defecation noted (scattered/ clumped) and replicated naturalistically in decomposition plots. Decomposition was monitored weekly until $\geqslant 90 \%$ of pellet groups had decayed. For faecal standing crop counts the density of animals was estimated as $D=c / p t$ (Laing et al., 2003).

The faecal accumulation rate method follows the same principle but uses the accumulation rate $a$ of pellets rather than decomposition rate. This requires repeated visits to the same quadrats. We established 20 quadrats of $10 \times 10 \mathrm{~m}$, stratified by habitat, using a combination system (Swanson et al., 2008). On the first visit the quadrat was marked permanently with corner posts and the location of the quadrat recorded with a global positioning system. A marker was inserted next to each pellet group, and its position and spatial distribution (scattered/piled/strung-out) were noted. Qualifying pellet groups comprised a minimum of six intact droppings. Whole groups outside but within $10 \mathrm{~cm}$ of the quadrat edge, and partial groups within the quadrat, were destroyed (Swanson et al., 2008). On subsequent visits the number of new pellet groups and the number of decomposed groups were recorded. Using the faecal accumulation rate, deer density was calculated as $D=c /$ (ap). All population densities were calculated per $\mathrm{km}^{2}$ and the results of the two methods were compared at both sites.

The time volunteers needed to relocate quadrats for the surveys of faecal accumulation rate was recorded, commencing when volunteers arrived within $100 \mathrm{~m}$ of the quadrat. Teams were provided with 1:25,000 maps, a compass and global positioning system, but no guidance from the scientists. This relocation time was compared with the time required by volunteers to set up a new quadrat for surveying the faecal standing crop within the same hectare.

\section{Comparison of volunteers with professionals}

All volunteer teams were accompanied by at least one scientist, facilitating direct comparison between the effectiveness of volunteers and professionals. We compared the time volunteer teams and a single professional required to set up new quadrats, the time all members of experienced teams (i.e. after having completed 20 surveys) and a single professional required to traverse a quadrat, and the total number of pellet groups found by an experienced team and a single professional in the same survey quadrat.

All volunteers were aware that scientists cross-checked their survey results. We acknowledge that, by definition, there are always inaccuracies in estimation but, for the purposes of comparison, the surveys by scientists were assumed to achieve $100 \%$ accuracy.

\section{Assessing volunteers}

Although population estimates were collected by teams of volunteers, performance assessments were of each volunteer (Newman et al., 2003). A random subsample of 100 volunteers (69 women and 31 men, to reflect the overall sex-ratio) was selected, with volunteers from 14 different teams, and appraised on a scale of $0-5$ (where 5 is the best performance; Newman et al., 2003), with both scientists (one male, one female) in attendance. Volunteers were free to traverse the quadrat at their own pace. Scientists followed volunteers across quadrats, upon completion of their survey, to verify the number of droppings found. Volunteers were also asked to identify the species that had produced the dropping piles, and identification was verified by the scientists.

We assessed volunteer ability (accuracy in the number of pellet groups found), identification skills (UK: accuracy in distinguishing droppings of fallow, roe and muntjac deer Muntiacus reevesi and in distinguishing these from European rabbit Oryctolagus cuniculus; Nova Scotia: identifying white-tailed deer droppings amongst droppings of porcupine Erethizon dorsatum and snowshoe hare 
Lepus americanus), and time taken to perform the survey, scored on a scale of o (very slow) to 5 (matching or beating the time of an experienced scientist). For time this relative scale was used rather than an absolute value, as the time required to search plots is related to the nature of the ground vegetation (Theuerkauf et al., 2008). We analysed the effects of gender, age (as $0, \leqslant 25$ years; $1,26-35 ; 2,36-45 ; 3,46-55 ; 4$, $56-66 ; 5, \geqslant 66)$, and volunteer willingness and aptitude to survey the ground closely. The latter is distinct from physical fitness (sensu Newman et al., 2003) as it comprises an assessment of the volunteers' enthusiasm as well as their physical flexibility.

Averaging (i.e. calculating the sum of all volunteer scores divided by the number of volunteers) over all survey plots provided an index of volunteer effectiveness, which enabled us to compare the accuracy of volunteer-based deer estimates with those of professionals. Effectiveness scores averaged with survey time scores provided an index of volunteer proficiency (Weist et al., 1961).

Volunteers were appraised twice: after having surveyed five quadrats (novice) and after 20 quadrats (experienced). Because of direct supervision and validation by scientists all dropping counts were deemed reliable and therefore all survey results were used for estimating the populations.

\section{Validation of survey estimates}

The surveys in Wytham Woods coincided with three major deer culls (winter months of 2000-2003: Savill et al., 2010). This enabled us to compare differences in inter-annual estimates of deer numbers derived from faecal pellet group counts with the numbers of deer shot during the culls. As detection rates for roe and fallow deer droppings were considered to be equal, the data for these species were combined to increase analytical power. Inter-annual productivity was estimated assuming that $75 \%$ of females were of breeding age and the sex ratio was 50:50, as evidenced from cull cohort data. This allowed population reductions, as a result of winter culling, to be modified by the addition of fawns inferred to be born in the subsequent spring. We acknowledge natural mortality, although we were unable to quantify this. All statistical analyses were performed using Minitab v. 15.1 (Minitab, State College, USA).

\section{Results}

Optimizing the survey method for volunteers

Estimates of faecal accumulation rate and faecal standing crop derived from 20 combination plots, combining weeks 3 and 6 did not differ significantly at either study site (Kruskal-Wallis-test: fallow deer $\mathrm{H}_{1,79}=0.31, \mathrm{P}=0.58$; roe deer $\mathrm{H}_{1,79}=0.28, \mathrm{P}=0.60$; white-tailed deer $\mathrm{H}_{1,79}=0.01$,
TABlE 2 Mean estimates of deer numbers (fallow and roe deer in Wytham Woods, UK, and white-tailed deer in Cook's Lake Farm, Nova Scotia; Table 1) derived from the faecal accumulation rate and faecal standing crop methods at 3 and 6 weeks and o, 3 and 6 weeks, respectively.

\begin{tabular}{lll}
\hline Survey type (by species) & Time (weeks) & Mean \pm SE \\
\hline Fallow deer & 3 & \\
Accumulation rate & 6 & $153.3 \pm 30.20$ \\
Standing crop & 0 & $148.5 \pm 24.40$ \\
& 3 & $159.3 \pm 36.20$ \\
& 6 & $164.8 \pm 34.60$ \\
& &
\end{tabular}

\section{Roe deer}

Accumulation rate

$75.3 \pm 21.00$

$66.5 \pm 12.80$

Standing crop

$57.8 \pm 12.60$

$66.5 \pm 13.40$

$52.0 \pm 12.50$

\section{White-tailed deer}

Accumulation rate

$21.5 \pm 6.02$

$14.1 \pm 3.66$

Standing crop

$14.1 \pm 3.63$

$11.9 \pm 2.12$

$15.5 \pm 3.57$

$\mathrm{P}=0.92$; Table 2), indicating that the error rates in both methods were similar and that including volunteer-derived decomposition rates in calculations of faecal standing crop did not lower the accuracy of the estimates.

Volunteer teams took significantly longer to relocate quadrats for faecal accumulation rate surveys established by previous teams (Wytham Woods: $29 \pm$ SE 1.93 minutes, $\mathrm{n}=20$; Cook's Lake Farm: $41 \pm \mathrm{SE} 2.39$ minutes, $\mathrm{n}=20$ ) than to establish new quadrats for estimating faecal standing crop (Wytham Woods: $5 \pm$ SE 0.30 minutes, $\mathrm{n}=20$; Cook's Lake Farm $7 \pm$ SE 0.34 minutes, $n=20$ ) within the same habitat type (paired $t$-test: Wytham Woods $t=11.97$, $\mathrm{P}<0.001$; Cook's Lake Farm $t=14.56, \mathrm{P}<0.001$ ). Because of the denser understorey, quadrats at Cook's Lake Farm took significantly longer to relocate (Wytham Woods: $29 \pm$ SE 4.61 minutes, $\mathrm{n}=20$; Cook's Lake Farm: $41.2 \pm$ SE 6.79 minutes, $\mathrm{n}=20$; paired $t$-test, $\mathrm{t}=-6.35, \mathrm{P}<0.001$ ) or establish (Wytham Woods: $5 \pm$ SE 0.92 minutes, $\mathrm{n}=20$; Cook's Lake Farm: $7 \pm$ SE 1.08 minutes, $\mathrm{n}=20$; paired $t$-test, $t=-6.02, \mathrm{P}<0.001)$.

\section{Estimating decomposition rate}

Pellet groups decomposed according to a Type-1 survivorship curve. Of the 120 pellet groups monitored weekly, with May and August replicates at both sites, $\geqslant 90 \%$ remained after 42 days and $>90 \%$ had decayed after 49 days. We found no significant differences between May and August 
TABLE 3 Mean \pm SE number of deer per $\mathrm{km}^{2}$, and extrapolated for each study site, using estimates of pellet group counts at Wytham Woods and Cook's Lake Farm (Table 1). For Wytham Woods cull data are provided and the impact of the cull on the numbers of fallow and roe deer in the subsequent year are predicted, taking into account the estimated number of fawns born, to facilitate comparison with pellet group estimates.

\begin{tabular}{|c|c|c|c|c|c|c|}
\hline Year & Species & No. per $\mathrm{km}^{2}$ & Extrapolated number & Cull & Fawns & Predicted \\
\hline \multicolumn{7}{|c|}{ Wytham Woods } \\
\hline \multirow[t]{2}{*}{2000} & Fallow & $41 \pm 3.08$ & 158 & 69 & 33 & \\
\hline & Roe & $14 \pm 1.34$ & 56 & 0 & 21 & \\
\hline \multirow[t]{2}{*}{2001} & Fallow & $34 \pm 2.97$ & 132 & 82 & 21 & 122 \\
\hline & Roe & $11 \pm 1.21$ & 42 & 12 & 11 & 77 \\
\hline \multirow[t]{2}{*}{2002} & Fallow & $24 \pm 1.97$ & 95 & 75 & 8 & 71 \\
\hline & Roe & $9 \pm 0.78$ & 34 & 15 & 7 & 41 \\
\hline \multirow[t]{2}{*}{2003} & Fallow & $9 \pm 1.17$ & 35 & & & 28 \\
\hline & Roe & $5 \pm 0.78$ & 20 & & & 26 \\
\hline \multirow[t]{2}{*}{2004} & Fallow & $18 \pm 1.93$ & 57 & & & \\
\hline & Roe & $3 \pm 0.78$ & 13 & & & \\
\hline \multirow[t]{2}{*}{2005} & Fallow & $9 \pm 1.55$ & 36 & & & \\
\hline & Roe & $6 \pm 0.93$ & 22 & & & \\
\hline \multicolumn{7}{|c|}{ Cook's Lake Farm } \\
\hline 2007 & White-tailed & $14 \pm 2.20$ & 16 & & & \\
\hline 2008 & White-tailed & $18 \pm 2.76$ & 25 & & & \\
\hline 2009 & White-tailed & $11 \pm 2.04$ & 16 & & & \\
\hline 2010 & White-tailed & $11 \pm 1.51$ & 15 & & & \\
\hline
\end{tabular}

replicates at Wytham Woods, roe and fallow combined (Mann-Whitney $U$-test: $\mathrm{n}_{1}=\mathrm{n}_{2}=120, \mathrm{P}=0.37$ ) or at Cook's Lake Farm for white-tailed deer (Mann-Whitney $U$-test: $\left.\mathrm{n}_{1}=\mathrm{n}_{2}=120, \mathrm{P}=0.82\right)$, indicating that decomposition rate could be extrapolated over all surveys.

\section{Verification of population estimates from faecal standing crop}

Table 3 presents estimates of annual deer density and extrapolations to mean deer numbers at each site. Estimates of faecal pellet group counts were significantly correlated with the decline in deer numbers through culling (roe and fallow combined: $\mathrm{n}=6$, Pearson's $\mathrm{R}=0.890, \mathrm{P}=0.017$; Table 3 ). Both species showed close, separate correspondence between pellet-group and cull measures of population decline that, because of the small sample sizes, only bordered significance (Pearson's correlation: fallow: $\mathrm{R}=0.983$, $\mathrm{P}=0.118$; roe: $\mathrm{R}=0.925, \mathrm{P}=0.248$ ).

\section{Comparison of volunteers with professionals}

On average volunteer teams found $68 \%$ of droppings located by professional biologists. However, as a single surveyor had to cross the quadrat 5-10 times, surveying a 1-2 $\mathrm{m}$ strip at a time, the possibility for double-counting the same dropping had to be minimized by marking (or remembering) previously recorded piles. As volunteers worked in teams, each team member traversed the quadrat only once, notifying their neighbours of already recorded droppings within their survey stretch, thus eliminating double-counts. Ensuring statistical randomness of survey locations was difficult, as volunteers tended to set out quadrats in 'promising locations' (i.e. where they found droppings/paths etc.), thus jeopardizing estimate accuracy.

Volunteer teams traversed quadrats significantly faster than a single professional (Wytham Woods: teams $3.2 \pm$ SE 1.81 minutes, single professional $13 \pm$ SE $1.76 \mathrm{~min}-$ utes, paired $t=-14.08, \mathrm{P}<0.005, \mathrm{n}=10$; Cook's Lake Farm: teams $7.6 \pm \mathrm{SE}_{3.17}$ minutes, single professional $16 \pm$ SE 2.5 minutes, paired $t$-test $=-5.44, \quad \mathrm{P}<0.005$, $\mathrm{n}=10$ ). However, volunteer teams took significantly longer to stake out the quadrat (Wytham Woods: teams 6.2 \pm SE 2.25 minutes, single professional $2 \pm$ SE $0.67 \mathrm{~min}-$ utes, paired $t=5.78, \mathrm{P}<0.005, \mathrm{n}=10$; Cook's Lake Farm: teams 9.1 \pm SE 3.96 minutes, single professional 5.1 \pm SE 0.99 minutes, paired $t=3.35, \mathrm{P}<0.01, \mathrm{n}=10)$. In addition, many teams engaged in lengthy ( $>5$ minutes) discussions about where to locate quadrats, and moving on to the next quadrat (c. $50 \mathrm{~m}$ distance) took teams significantly longer than a single surveyor (Wytham Woods: teams 10.3 \pm SE 3.4 minutes, single professional $3.2 \pm \mathrm{SE} 1.14$ minutes, paired $t=6.34, \mathrm{P}<0.005, \mathrm{n}=10$; Cook's Lake Farm: teams $15 \pm$ SE 6.16 minutes, single professional $6.1 \pm$ SE $1.66 \mathrm{~min}-$ utes, paired $t=4.8, \mathrm{P}<0.005, \mathrm{n}=10)$.

\section{Assessing volunteers}

Volunteer performance increased significantly with training and experience. After five quadrats effectiveness averaged 
$3.39 \pm$ SE 0.64. By this point volunteers could find and identify correctly a mean of $68 \%$ of droppings. A variety of individual-specific parameters affected performance. After five quadrats men had significantly higher effectiveness (men: $2.6 \pm$ SD 0.68 ; women $2.2 \pm \mathrm{SD} 0.95 ; F_{1,88}=7.39$, $\mathrm{P}=0.008$ ) and proficiency scores (men: $2.60 \pm \mathrm{SD} 0.67$; women: $2.10 \pm$ SD 0.55; $\left.F_{1,88}=18.91, \mathrm{P}=0.001\right)$, predominantly because of shorter survey times (men: $2.77 \pm$ SD 0.77; women: $\left.1.93 \pm \mathrm{SD} 0.73 ; F_{1,88}=23.09, \mathrm{P}=0.001\right)$. After 20 quadrats this effect of gender was still evident for overall survey proficiency $\left(F_{1,88}=5.20, \mathrm{P}=0.025\right)$, with men (3.60 \pm SD 0.62) continuing to score higher than women $(3.41 \pm S D 0.65)$. The gender difference in effectiveness observed in novices, however, was no longer significant (men: $3.47 \pm$ SD 0.68; women: $3.36 \pm$ SD 0.95; $F_{1,88}=2.15$, $\mathrm{P}=0.146$ ), although survey time persisted as the most influential component of gender-related differences, bordering significance (men: $3.7 \pm$ SD o.88; women: $3.36 \pm$ SD 0.94; $\left.F_{1,88}=3.82, \mathrm{P}=0.050\right)$. In novices gender affected the ability to find droppings (men: $2.57 \pm \mathrm{SD} 0.94$; women: $2.12 \pm$ SD 1.39; $F_{1,88}=4.63, \mathrm{P}=0.034$ ), although this effect was no longer apparent by quadrat 20 , indicating that women improved more with practice.

Willingness and aptitude were related significantly to ability (at five quadrats: $F_{1,88}=11.30, \mathrm{P}=0.001$; at 20 quadrats: $F_{1,88}=19.74, \mathrm{P}=0.001$ ), as well as to effectiveness (five quadrats: $F_{1,88}=5.64, \mathrm{P}=0.001 ; 20$ quadrats $F_{1,88}=5.39$, $\mathrm{P}=0.001$ ), but not to proficiency (five quadrats: $F_{1,88}=1.36$, $\mathrm{P}=0.25 ; 20$ quadrats: $\left.F_{1,88}=1.97, \mathrm{P}=0.092\right)$. Higher willingness and aptitude also improved identification scores significantly by 20 quadrats $\left(F_{1,88}=2.39, \mathrm{P}=0.044\right)$ but not by five quadrats $\left(F_{1,88}=1.34, \mathrm{P}>0.20\right)$. Volunteer age, however, showed no effects. Although the small sample size $(\mathrm{n}=4)$ prohibited statistical evaluation, we observed that men with visual deuteranomaly (i.e. red/green colour blindness) were barely able to detect droppings against a variety of types of ground cover (averaging only $16 \%$ of droppings found in the experimentally stocked sample quadrats).

\section{Discussion}

Using volunteers for ecological surveying is contentious. The U.S. House of Representatives asserted that volunteers are incompetent and biased, and prohibited the National Biological Survey from accepting volunteer services (Congressional Record H7488). By contrast, many recent large-scale surveys (e.g. the Protea Atlas of South Africa, 2013, and the Evolution MegaLab, 2013) are based on data collected by volunteers (Silvertown et al., 2013). Our objective was to develop a survey method for deer management, suited to deployments of novice volunteers working in teams, to ensure supervision and safety. Faecal pellet group counts by all sorts of people have been used since the 1930s (Bennett et al., 1940). Although the faecal accumulation rate method is favoured by biologists (Campbell et al., 2004), its suitability is limited when working with volunteers who do not return because the first team is denied the gratification of generating population estimates, which is important for motivation (Cnaan \& Goldberg-Glen, 1991; Harrison, 1995; Buesching et al., in press). In addition, later teams have to locate established quadrats, which takes significantly longer than the establishment of quadrats for surveying faecal standing crop (Campbell et al., 2004). The cumulative effect of $20 \times 30-40$ minutes of searching affects the well-being of older or less fit volunteers (Buesching et al., 2005), with other volunteers losing interest.

Estimates of faecal accumulation rate did not differ significantly from estimates of faecal standing crop. When working with volunteer teams, the faecal standing crop method thus saves time, and the concurrent monitoring of decomposition rates provides an extra activity. However, to minimize loss of time, trails to decomposition plots need to be easily accessible and marked clearly.

Overall, estimates based on volunteer data underestimated deer densities by c. $30 \%$, as not all droppings were counted. Although scientists consistently verified species identification, volunteers identified only $68 \%$ of droppings correctly. Volunteer accuracy without constant supervision and training is likely to be considerably lower (Foster-Smith \& Evans, 2003). In addition, volunteers were prone to skewing data by selecting quadrat locations that would maximize their chances of success of finding droppings. These tendencies were particularly pronounced when surveying in areas of low deer (and thus dropping) density, and would thus be likely to result in marked overestimates of density. To counteract high error rates a professional biologist needs to supervise volunteer teams at all times. As deer surveys are frequently undertaken without prior knowledge of population size, verification of derived population estimates can be difficult. Our study overlapped annual deer culls at Wytham Woods (Savill et al., 2010), and reductions in population estimates based on faecal standing crop surveys correlated significantly with the declines imposed by culling, mirroring results from Kielder Forest, UK (McIntosh et al., 1995) and Anticosti Island, Québec, Canada (Pettorelli et al., 2007). In contrast, at Cook's Lake Farm hunting quotas were designed to maintain a constant deer density, and our faecal standing crop surveys returned remarkably consistent estimates.

When using volunteers, scientists commonly expect to collect more data per unit time than when working alone, and the accuracy of estimates of deer density can be improved by increasing the number of survey quadrats (Smart et al., 2004). Volunteer proficiency averaged 3.46 , or $68 \%$, with volunteers becoming more efficient between plots five and 20, highlighting the importance of field training and 
practice (Foster-Smith \& Evans, 2003; Newman et al., 2003). Although volunteers working as a team of 5-10 surveyors completed a survey in c. $30 \%$ of the time of a single professional, thus resulting in considerable time saving, loss of time between quadrats (e.g. reaching the next survey location, establishing the next quadrat) was considerable compared to a single scientist. In addition, the initial training is time consuming (Dickinson et al., 2010) because volunteers need to understand the importance of their contribution (Green et al., 1997) and they appreciate having theory and survey protocols explained to them (Silvertown et al., 2013). Thus, cost-effective deployment of volunteers is a question of survey scale (Silvertown et al., 2013). The combined training took c. 5 hours, which was c. $25 \%$ of the time spent collecting data (i.e. 20 hours). One scientist needed on average only 18.2 minutes (Wytham Woods) and 27.2 minutes (Cook's Lake Farm) to reach, mark out and survey one quadrat, whereas teams needed 19.7 minutes (Wytham Woods) and 35.3 minutes (Cook's Lake Farm) per quadrat. Thus, one scientist could expect to survey between 44 (Cook's Lake Farm) and 66 (Wytham Woods) quadrats in 20 hours, whereas volunteers only surveyed 25 (Cook's Lake Farm) and 46 (Wytham Woods) quadrats in this time, lowering the potential productivity of scientists by c. $30 \%$ (Cook's Lake Farm) and 43\% (Wytham Woods). Although productivity was reduced by involving volunteers in our study, it is possible that on other projects experienced volunteers could be sent to survey without the involvement of scientists, thus genuinely contributing to data collection (Silvertown et al., 2013).

Team composition can vary substantially (Buesching et al., 2005), and judging individual strengths and weaknesses of new volunteers without detailed observation or specific tests can be difficult. Thus, identifying the effects of generic factors on volunteer performance is important to ensure effective deployment (Diefenbach et al., 2003). Survey protocols need to be matched to the modal volunteer but also to consider limitations imposed by those least able (Brown, 1999).

Men and women consistently exhibited different skills. Although both genders improved between plots five and 20, men appeared to be more able at the outset and women improved with practice. Age did not affect capabilities but willingness and aptitude did. Some volunteers were hampered physically by a lack of suppleness, affecting bending and probing the ground, and others had the ability but were deterred by the notion of examining faecal material (although volunteers were not required to handle pellets and gloves were available) and thus their relative performance was compromised (by quadrat 20 their identification skills were significantly impaired, as people appeared to learn predominantly through hands-on experience (see also Prestby et al., 1990). Most counts underestimate pellet density as droppings are missed because of vegetation overgrowth, partial decay, and inadequate survey effort (Mackenzie \& Kendall, 2002). Newman et al. (2003) reported that in artificially stocked plots volunteers initially found $71 \%$ of pellet groups but performance declined with repetition because volunteers became more blasé as the novelty of the work wore off, illustrating that amateurs can lose focus if techniques are elaborate, repetitive or abstracted. As a result of this mismatch between the realities of research vs expectations of 'exciting hot science' (Earthwatch, 2010), volunteers need special instruction and guided deployment to avert adverse effects of the expectancy-disconfirmation paradigm (Yüksel \& Yüksel, 2001), and tasks have to be varied and interesting to ensure data quality (Silvertown et al., 2013). Correlation between conceived success rate and volunteer motivation is well known (Prestby et al., 1990). For example, starting with survey quadrats where pellet groups were not found proved disheartening to volunteers, whereas starting new teams by accessing pellet-rich sites boosted morale and thus accuracy. As these disproportionately pellet-rich quadrats would have skewed analyses, training quadrats were not used for estimating populations, thus costing scientists time without returning data.

Analysing survey results with each team proved important, as amassing data without seeing the product of their labour left volunteers feeling disenfranchised (Silvertown et al., 2013). In weekly classroom sessions we explained the mathematics of turning dropping counts into mean deer densities but this required an additional hour of scientists' time in management of the volunteers.

We conclude that involvement of volunteers in data collection can be a time- and cost-effective alternative to ecological monitoring by professionals if volunteers can work for a project long enough to either collect data beyond what the scientist could have collected in the time spent on training, supervision and extra data analysis, and/or work independently of supervision.

\section{Acknowledgements}

We are grateful for continuing support from the Earthwatch Institute, which has allowed us to undertake this study. We thank the Mammals Trust UK for supplementary support, and Nigel Fisher for cull data from Wytham Woods.

\section{References}

Bennett, L.J., English, P.F. \& McCain, R. (1940) A study of deer populations by use of pellet-group counts. The Journal of Wildlife Management, 4, 398-403.

Brown, E. (1999) Assessing the value of volunteer activity. Nonprofit and Voluntary Sector Quarterly, 28, 3-17.

Buesching, C.D., Newman, C., Jones, J.T. \& Macdonald, D.W. (2011) Testing the effects of deer grazing on two woodland rodents, bank voles and woodmice. Basic and Applied Ecology, 12, 207-214. 
Buesching, C.D., Newman, C. \& Macdonald, D.W. (2005) Volunteers in ecological research: amateur ecological monitors: the benefits and challenges of using volunteers. Bulletin of the British Ecological Society, 36, 20-22.

Buesching, C.D., Slade, E., Newman, C., Riordan, P. \& Macdonald, D.W. (in press) Citizen Science in Wytham Woods: collecting scientific data using amateur volunteers. In Wildlife Conservation on Farmland (eds D.W. Macdonald \& R.E. Feber). Oxford University Press, Oxford, UK.

Campbell, D., Swanson, G.M. \& Sales, J. (2004) Methodological insights: comparing the precision and cost-effectiveness of faecal pellet group count methods. Journal of Applied Ecology, 41, $1185-1196$.

CBD (Convention on Biological Diversity) (2013) Text of the CBD. Http://www.cbd.int/convention/text/ [accessed 27 January 2014].

Chatn, R.A. \& Goldberg-Glen, R.S. (1991) Measuring motivation to volunteer in human services. The Journal of Applied Behavioral Science, 27, 269-284.

Dickinson, J.L., Zuckerberg, B. \& Bonter, D.N. (2010) Citizen science as an ecological research tool: challenges and benefits. Annual Review of Ecology, Evolution, and Systematics, 41, 149-172.

Diefenbach, D.R., Brauning, D.W. \& Mattice, J.A. (2003) Variability in grassland bird counts related to observer differences and species detection rates. The Auk, 120, 1168-1179.

Evolution MegaLab (2013) Http://evolutionmegalab.org [accessed 10 December 2013].

Earthwatch (2010) Earthwatch Institute. Http://earthwatch.org [accessed 2010]

Foster-Smith, J. \& Evans, S.M. (2003) The value of marine ecological data collected by volunteers. Biological Conservation, 113, 199-213.

Fuller, R.J. \& Gill, R.M.A. (2001) Ecological impacts of increasing numbers of deer in British woodland. Forestry, 74, 193-199.

GiLL, R.M.A. (2006) The influence of large herbivores on tree recruitment and forest dynamics. In The Impact of Large Mammalian Herbivores on Biodiversity, Ecosystem Structure and Function (eds K. Danell, R. Bergstrom \& T. Rooke), pp. 170-202. Cambridge University Press, Cambridge, UK.

Gill, R.M.A. \& Fuller, R.J. (2007) The effects of deer browsing on woodland structure and songbirds in lowland Britain. Ibis, $149,119-127$.

Gilmour, J. \& SAunders, D.A. (1995) Earthwatch: an international network in support of research on nature conservation. In Nature Conservation 4: The Role of Networks (ed. D.D. Saunders), pp. 627-633. Surrey Beatty, Chipping Norton, Australia.

Green, D., Askins, G.R. \& West, P.D. (1997) Public opinion: obstacle or aid to sound deer management? Wildlife Society Bulletin, $25,367-370$.

HARRISON, D.A. (1995) Volunteer motivation and attendance decisions: competitive theory testing in multiple samples from a homeless shelter. Journal of Applied Psychology, 80, 371-385.

Laing, S.E., Buckland, S.T., Burn, R.W., Lambie, D. \& Amphlett, A. (2003) Dung and nest surveys: estimating decay rates. Journal of Applied Ecology, 40, 1102-1111.

Macdonald, D.W., Mace, G. \& Rushton, S. (1998) Proposals for Future Monitoring of British Mammals. HMSO, London, UK.

MacKenzie, D.I. \& Kendall, W.L. (2002) How should detection probability be incorporated into estimates of relative abundance? Ecology, 83, 2387-2393.

Mayle, B.A., Peace, A.J. \& Gill, R.M.A. (1999) How Many Deer? A Field Guide to Estimating Deer Populations. Forestry Commission, Edinburgh, UK.
Mayle, B.A. \& Staines, B.W. (1998) An overview of methods used for estimating the size of deer populations in Great Britain. In Population Ecology, Management and Welfare of Deer (eds C.R. Goldspink, S. King \& R.J. Putman), pp. 19-31. Manchester University Press, Manchester, UK.

McIntosh, R., Burlton, F.W.E. \& McReddie, G. (1995) Monitoring the density of a roe deer Capreolus capreolus population subjected to heavy hunting pressure. Forest Ecology and Management, 79, 99-106.

Mitchell, B., Rowe, J.J., Ratcliffe, P.R. \& Hinge, M. (1985) Defecation frequency in roe deer (Capreolus capreolus) in relation to the accumulation rates of faecal deposits. Journal of Zoology, $207,1-7$.

Newman, C. \& Buesching, C.D. (2004a) Getting on the right track. Deer: The Journal of the British Deer Society, 12, 20-22.

Newman, C. \& Buesching, C.D. (2004b) Name droppings. Deer: The Journal of the British Deer Society, 13, 12-15.

Newman, C., Buesching, C.D. \& Macdonald, D.W. (2003) Validating mammal monitoring methods and assessing the performance of volunteers in wildlife conservation - "Sed quis custodiet ipsos custodies?”. Biological Conservation, 113, 189-197.

Patterson, B.R., MacDonald, B.A., Lock, B.A., Anderson, D.G. \& Benjamin, L.K. (2002) Proximate factors limiting population growth of white-tailed deer in Nova Scotia. The Journal of Wildlife Management, 66, 511-521.

Pettorelli, N., Côté, S., Gingras, A., Potvin, F. \& Huot, J. (2007) Aerial surveys vs hunting statistics to monitor deer density: the example of Anticosti Island, Québec, Canada. Wildlife Biology, 13, 331-327.

Plumptre, A.J. \& Harris, S. (1995) Estimating the biomass of large mammalian herbivores in a tropical montane forest: a method of faecal counting that avoids assuming a 'steady state' system. Journal of Applied Ecology, 32, 111-120.

Prestby, J.E., Wandersman, A., Florin, P., Rich, R. \& Chavis, D. (1990) Benefits, costs, incentive management and participation in voluntary organizations: a means to understanding and promoting empowerment. American Journal of Community Psychology, 18, 117-149.

Protea Atlas (2013) Protea Atlas Project. Http://www.proteaatlas.org.za/ [accessed 27 January 2014].

Savill, P.S., Perrins, C.M., Kirby, K.J. \& Fisher, N. (eds) (2010) Wytham Woods: Oxford's Ecological Laboratory. Oxford University Press, Oxford, UK.

Silvertown, J., Buesching, C.D., Jacobson, S., Rebello, T. \& Birtles, A. (2013) Citizen science and nature conservation. In Key Topics in Conservation Biology 2 (eds D.W. Macdonald \& K. Willis), pp. 127-142. Wiley-Blackwell, Chichester, UK.

Smart, J.C.R., Ward, A.I. \& White, P.C.L. (2004) Monitoring woodland deer populations in the UK: an imprecise science. Mammal Review, 34, 99-114.

Spielman, A. (1994) The emergence of Lyme disease and human babesiosis in a changing environment. Annals of the New York Academy of Sciences, 740, 146-156.

Swanson, G., Armstrong, H. \& Campbell, D. (2008) Estimating deer abundance in woodlands: the combination plot technique. Forestry Community Bulletin, 128.

Theuerkauf, J., Rouys, S. \& Jedrzejewski, W. (2008) Detectability and disappearance of ungulate and hare faeces in a European temperate forest. Annales Zoologici Fennici, 45, 73-80.

Wiest, W.M., Porter, L.W. \& Ghiselli, E.E. (1961) Relationship between individual proficiency and team performance and efficiency. Journal of Applied Psychology, 45, 435-440.

Yúksel, A. \& YÚkSel, F. (2001) The expectancy-disconfirmation paradigm: a critique. Journal of Hospitality \& Tourism Research, 25, 107-131. 


\section{Biographical sketch}

The authors are interested in the long-term effects of environmental and climatic factors on the population dynamics of terrestrial mammals, ranging from small mammals to ungulates and carnivores. Often using the European badger Meles meles as a model species, we investigate life history paradigms relating to reproductive biology, olfactory communication, stress, parasitology, and territoriality, employing methods from endocrinology, genetics, scent analyses and tracking. As many of our research questions require long-term data we started investigating the use of amateur volunteers as citizen scientists. 